Stephanie Jungheim

\title{
Medienordnung und Wettbewerbsrecht im Zeitalter der Digitalisierung und Globalisierung
}



2012. XXI, 761 Seiten. JusPubl 214

ISBN 978-3-16-152017-4

DOI 10.1628/978-3-16-152017-4

eBook PDF $184,00 €$

ISBN 978-3-16-150928-5

Leinen $184,00 €$
Die Medienlandschaft verändert sich derzeit schneller als je zuvor. Die faktischen Änderungen der Medienwelt, zu der auch Änderungen der Mediennutzung gehören, werfen die Frage auf, wie unter Zugrundelegung des verfassungsrechtlichen Vielfaltsgebots künftig eine deutsche Medienordnung ausgestaltet werden kann, die sich in die Vorgaben des europäischen und internationalen Rechts einfügt. In Abkehr von dem bisherigen Ansatz des Bundesverfassungsgerichts, den Rundfunk separiert als eigenständigen Mikrokosmos zu betrachten, in dem eine gleichgewichtige Vielfalt zu gewährleisten ist, wird das Vielfaltsgebot als Rechtsprinzip interpretiert, welches auf die Vielfalt im gesamten Mediensystem abstellt. Dadurch rückt die Verhinderung vorherrschender Meinungsmacht in den Mittelpunkt und ist der Leitfaden für den Entwurf des künftigen Nebeneinanders von Medienkonzentrationsrecht, Kartellrecht und Telekommunikationsrecht.

Stephanie Jungheim Studium der Wirtschaftswissenschaften in Nürnberg; 2001 Promotion; 2009 Habilitation; derzeit Referentin in der 6. Beschlussabteilung des Bundeskartellamtes (u. a. Medien und Sport) und Privatdozentin an der Universität Erlangen-Nürnberg.

Jetzt bestellen:

https://mohrsiebeck.com/buch/medienordnung-und-wettbewerbsrecht-im-zeitalter-der-digitalisierung-und-globalisierung9783161520174?no_cache=1

order@mohrsiebeck.com

Telefon: $+49(0) 7071-923-17$

Telefax: $+49(0) 7071-51104$ 